\title{
Metabolic Syndrome: The Complex Relationship of Diet to Conditions of Disturbed Metabolism
}

\section{Jeffrey S. Bland*}

Metagenics, Inc., $977044^{\text {th }}$ Ave NW, Ste 100, Gig Harbor, WA 98332, USA

Running title: Diet and Disturbed Metabolism

Corresponding author: Jeffrey S. Bland, PhD

Submission date 15 December 2010; Acceptance date 13 February 2011; Publication date 14 February 2011

*The article by Dr. Jeffrey S. Bland is based on his respective talk at the American Society for Nutrition Satellite Symposium at the Annual Meeting of Experimental Biology on April 23, 2010, in Anaheim, CA, entitled, "Emerging clinical applications of diet and supplemental phytochemicals for metabolic syndrome and obesity".

\begin{abstract}
The widespread prevalence and deleterious effects of metabolic syndrome have become a major public health challenge as it is associated with the development of type 2 diabetes and cardiovascular disease. Lifestyle modification focusing on diet has shown promise for managing cardiovascular disease risk, and clinical studies provide evidence that a Mediterranean diet supplemented with phytochemicals is a successful interventional approach. The role of phytochemicals in regulating gene expression and modulating intracellular kinase activity has only recently begun to be appreciated. Clinical studies investigating the effects of specific phytochemicals in metabolic syndrome patients have produced encouraging results, including normalization of metabolic function, reduction of cardiovascular risk, and resolution of metabolic syndrome. As research advances our understanding of the evolutionary relationships between plants and humans, details are emerging about the mechanisms by which phytochemicals regulate insulin signaling and inflammatory responses. This expanding field of research is likely to lead to novel, effective clinical approaches for combating chronic diseases such as metabolic syndrome.
\end{abstract}




\section{Key words}

Metabolic syndrome, Mediterranean diet, xenohormesis, phytochemicals, low-glycemic-load diet, Humulus lupulus, Acacia nilotica

\section{Introduction}

In 1949, H.P. Himsworth at the London School of Medicine authored a paradigm-shifting article in the Lancet entitled "The syndrome of diabetes mellitus and its causes" [1]. He proposed that there was a type of diabetes that was not related to the lack of insulin secretion from beta cells of the pancreas, but rather to the lack of sensitivity to the insulin signal at the peripheral tissue level [1]. In 1984, G.M. Reaven at Stanford School of Medicine described a comparable disruption of insulin action upon insulin sensitive tissues that was associated with risk to both diabetes and cardiovascular disease, which he later termed Syndrome X [2]. Reaven described this syndrome as a diet sensitive condition [2]. It was subsequently referred to as "metabolic syndrome," characterized by hyperinsulinemia and insulin resistance. The constellation of factors that define metabolic syndrome are described in Figure 1.

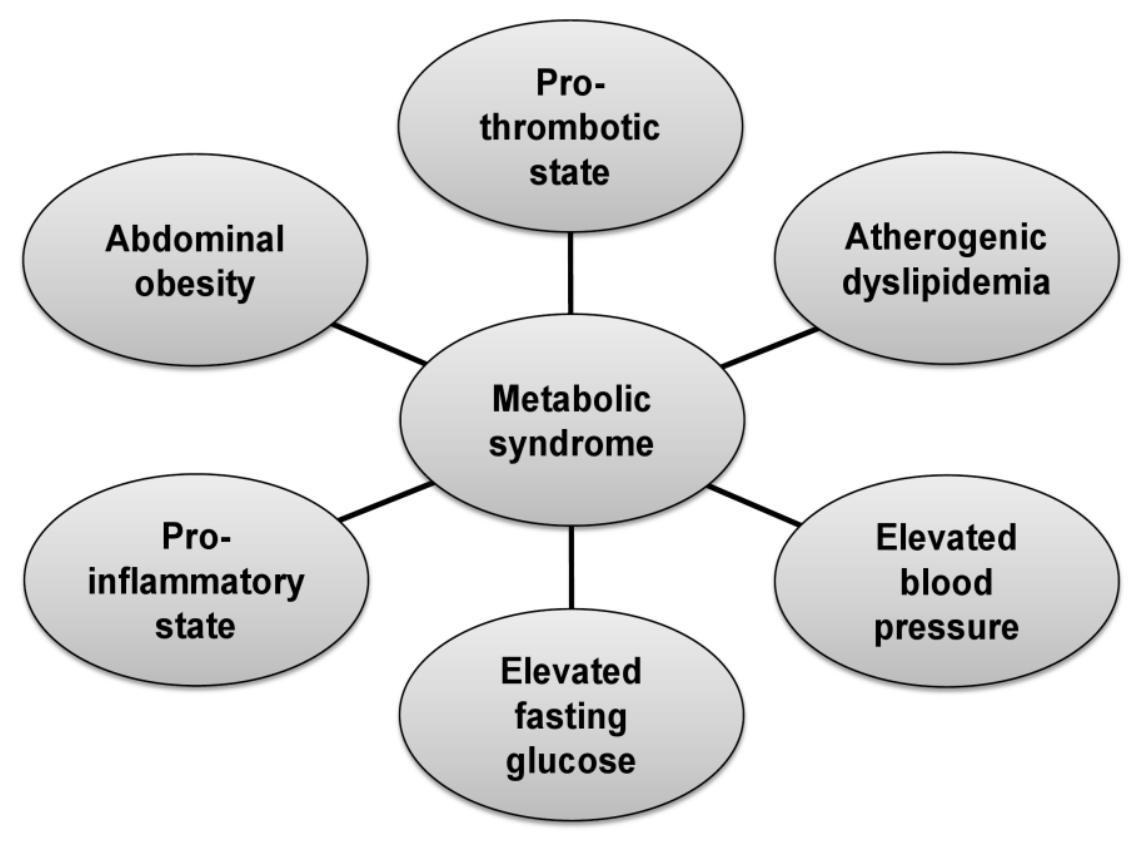

Figure 1. Constellation of factors contributing to the metabolic syndrome according to the diagnostic guidelines by Grundy et al. [17]. Abdominal obesity is referred to as a waist circumference of $\geq 102 \mathrm{~cm}$ (40 in) in men and $\geq 88 \mathrm{~cm}$ (35 in) in women. Atherogenic dyslipidemia refers to triglycerides of $\geq 1.7$ $\mathrm{mmol} / \mathrm{L}(150 \mathrm{mg} / \mathrm{dL})$ or pharmaceutical therapy for hypertriglyceridemia, as well as low HDL, defined as $<1.03 \mathrm{mmol} / \mathrm{L}(40 \mathrm{mg} / \mathrm{dL})$ in men or $<1.3 \mathrm{mmol} / \mathrm{L}(50 \mathrm{mg} / \mathrm{dL})$ in women or pharmaceutical therapy for low HDL. Elevated fasting blood glucose refers to levels $\geq 5.55 \mathrm{mmol} / \mathrm{L}(100 \mathrm{mg} / \mathrm{dL})$ or pharmaceutical treatment for elevated glucose. Elevated blood pressure is $\geq 130 \mathrm{~mm} \mathrm{Hg}$ systolic blood pressure or $\geq 85$ $\mathrm{mm} \mathrm{Hg}$ diastolic blood pressure or pharmaceutical therapy for hypertension. Meeting any 3 of 5 criteria 
constitutes diagnosis of metabolic syndrome. Finally, increased thrombosis and inflammation are recent additions to the metabolic syndrome cascade. Reproduced with permission from [36].

The 2010 report of the WHO Expert Consultation Committee defined metabolic syndrome as a pre-morbid condition rather than a clinical diagnosis, and they suggested that it should exclude individuals with established diabetes or known cardiovascular disease [3]. Grundy described the "metabolic syndrome pandemic" as a metabolic disturbance that is related to a multiplex of several risk correlates of metabolic origin, and which affects as much as $24 \%$ of the adult population in the United States and is growing rapidly in prevalence throughout the world [4]. Metabolic syndrome has been linked to dyslipidemia, hypertension, hyperglycemia, and a prothrombotic and proinflammatory state [5]. Controversy has persisted as to whether metabolic syndrome is caused by obesity or merely correlates with central obesity. Recently a joint statement of the International Diabetes Task Force on Epidemiology and Prevention, National Heart, Lung and Blood Institute, American Heart Association (AHA), World Health Federation, International Atherosclerosis Society, and the International Association for the Study of Obesity concluded that increase in girth (i.e. waist circumference) was not a primary biomarker required for the definition of metabolic syndrome [6]. Nevertheless, metabolic syndrome with and without central obesity has been associated not only with increased risk for type 2 diabetes and cardiovascular disease, but also with polycystic ovarian syndrome, erectile dysfunction, sleep apnea, non-alcoholic fatty liver disease, hypertension, breast and colon cancer, and cognitive impairment related to a variant form of Alzheimer's disease [7-11].

\section{Relationship between metabolic syndrome and diet}

Based upon this evolution of consideration since 1984, the current state of understanding is that metabolic syndrome represents the consequence of a complex interplay of genes and environment resulting in metabolic disturbances and increased risk for many chronic diseases. Specific dietary factors have been identified as key environmental agents that compromise metabolic function [12]. Considerable discussion has focused on determining the preferential dietary pattern for the prevention and management of metabolic syndrome. A food plan that incorporates a low glycemic load has been found to improve insulin signaling and reduce metabolic risk factors [13]. Replacement of refined carbohydrates with protein in the diet was found to be advantageous for the management of metabolic syndrome [14], as was a reduction in saturated fat and an increase in omega-3 oils $[15,16]$.

The dietary plan that is emerging as the superior approach for the management of metabolic syndrome is the Mediterranean diet [17]. A systematic review of thirty-five intervention studies concluded that this dietary approach demonstrated favorable effects on lipoprotein levels, endothelial function, insulin sensitivity, and cardiovascular function, including a reduction in carotid artery intima-media thickness [18]. Others reported that the Mediterranean diet reduced cellular and circulating inflammatory markers associated with atherosclerosis [19]. 
The role of the Mediterranean diet in managing conditions of insulin resistance is also consistent with the demonstrated value of this dietary approach for the management of newly diagnosed type 2 diabetes [20, 21]. In the Healthy Aging Longitudinal Study in Europe (HALE study) of individuals 70 to 90 years of age, consumption of a Mediterranean diet and healthful lifestyle was associated with a more than 50\% lower rate of all-cause mortality and reduction in both diabetes and cardiovascular diseases, compared to an age-matched control group of people maintaining their normal dietary and lifestyle patterns [22].

\section{The role of specific phytochemicals as a component of the Mediterranean diet on metabolic syndrome}

The Mediterranean diet is low in refined carbohydrates, sugars, and saturated and trans fats, and high in fiber, monounsaturated and polyunsaturated oils, and phytochemicals. Schiltz et al. emphasized the diversity of phytochemical-rich foods in the Mediterranean diet as a primary factor for its success in managing conditions associated with insulin resistance [23]. In a companion article, "Metabolic Syndrome and the Components of the Mediterranean Diet", Dr. Maria Luz Fernandez presents evidence that consumption of a Mediterranean-style diet is associated with reduced risk for heart disease and type 2 diabetes, and illustrates how several components of the Mediterranean diet have a positive impact on symptoms of metabolic syndrome.

Studies of the Mediterranean diet, such as in the recent trial conducted by Camargo et al., illustrate the importance of gene-diet interactions in disease modification [24]. Specifically, certain phytochemicals can differentially modulate the postprandial gene expression profile in people with metabolic syndrome and help to normalize disturbed metabolic functions associated with this condition.

Most recently, it has been suggested that phytochemicals produced in environmentally stressed plants have beneficial effects on the reduction of metabolic stress for animals that consume them. This relationship between humans and stress compounds in plants has been termed "xenohormesis" [25]. Between 5,000 and 10,000 phytochemicals have been identified, and the average daily intake of these phytochemicals from a standard diet is estimated at 1.5 grams [26]. Individuals consuming the Mediterranean diet ingest significantly more phytochemicals than people consuming the standard American diet [27], and the additive and synergistic effects of phytochemicals provide desirable health benefits beyond basic nutrition in reducing the risk for chronic disease [28]. Recent food recall studies have found that 8 out of 10 Americans have a "phytonutrient gap," such that their daily diet lacks between $69 \%$ and $88 \%$ of important xenohormetic phytochemicals, which could potentially result in adverse metabolic outcomes [29].

Recently Babish et al. reported results from a screening of phytochemicals from 206 foods and spices for activity on components of insulin signaling pathways [30]. The authors 
determined that a number of Mediterranean diet-associated food and spice extracts possessed significant insulin sensitizing bioactivity. These observations have been supported by additional studies. For example, Gymnema sylvestre extract, which has been used for the treatment of diabetes in India for centuries, possesses anti-diabetic phytochemicals [31]. The prickly pear cactus (Opuntia ficus-indica), which has been used in traditional medicine for diabetes by native Central and North Americans, contains insulin sensitizing phytochemicals [32]. Ethanolic extract of licorice (Glycyrrhiza uralensis Fisher) was reported to contain phytochemicals that bind to peroxisome proliferator-activated receptor gamma and reduce the metabolic disturbances in diabetic mice [33]. Minich and Bland examined reports on the clinical efficacy and safety of crucifer-derived phytochemicals in regulating steroid hormone metabolism and speculated on how they might modulate risk to chronic disease [34]. Recently a placebo controlled study evaluating the activities of various phytochemicals from green tea (epigallocatechin gallate), grapes (resveratrol), tomato (lutein), and soy oil (tocopherol) was conducted in overweight individuals [35]. The authors observed that supplementation with the phytochemical extract resulted in the reduction of risk factors associated with inflammation and oxidative and metabolic stress [35]. Further, compounds in many berry species have been identified as antioxidants or anti-diabetics. An expanded discussion on the bioactive properties of berries may be found in the companion article by Dr. Mary Ann Lila, "Impact of Bioflavonoids from Berryfruits on Biomarkers of Metabolic Syndrome".

\section{Putative mechanism of action of phytochemicals in metabolic syndrome}

In a review by Minich and Bland, the authors suggested that due to the complexity of metabolic syndrome, tailored dietary approaches including the evaluation of phytochemical content would be important [36]. This is an area that deserves much more research attention. Lukaczer et al. conducted an intervention trial in participants with metabolic syndrome who were randomized to either the AHA Step 1 diet or a low-glycemic-load diet supplemented with soy protein (containing isoflavones) and phytosterols [37]. They found significant improvements in cardiovascular risk factors in the group that received the phytochemical-enriched diet [37]. Izzo et al. reported that individuals with metabolic syndrome had a reduction in central obesity and improvements in lipid profile, diastolic blood pressure, and Framingham Risk Scores after eight weeks of phytochemical supplementation [38].

Mechanistic studies have found that specific phytochemicals regulate insulin signaling through complex nutrigenomic and intracellular signaling networks (reviewed in [36]). For example, Barnes reported that plant polyphenols influence gene expression, transcription, and protein expression and function, preventing metabolic disturbance in cellular systems [39]. Chung et al. reported that dietary polyphenols activate the Sirtuin 1 gene, which regulates metabolism, stress resistance, cellular survival, cellular senescence/aging, inflammation-immune function, endothelial functions, and circadian rhythms [40]. 
Further, there is an increasing body of literature indicating that specific phytochemicals have discrete actions on kinase-mediated intracellular signaling processes that are disrupted in patients with chronic diseases. For instance, flavonoids have been found to bind to Akt/protein kinase B (PKB), Fyn, Janus kinase 1 (JAK1), mitogen-activated protein kinase kinase 4 (MKK4) and phosphoinositide-3-kinase (PI3K) [41]. Adipocytes isolated from insulin resistant patients exhibit impaired insulin signaling, reduced insulin receptor substrate-1 (IRS-1) gene and protein expression, and dysfunctional insulin-stimulated PI3K and Akt/PKB signaling [42]. Minich et al. reported that phytochemical extracts from Humulus lupulus (hops) and Acacia nilotica selectively modulated kinases within the insulin signaling cascade and produced favorable insulin sensitizing effects in 3T3-L1 mouse adipocytes and in diabetic $d b / d b$ mice [43]. Tan et al. demonstrated that an extract from bitter melon (Momordica charantia) had agonist activity for AMP-activated protein kinase (AMPK) in 3T3-L1 adipocytes and enhanced glucose disposal in insulin-resistant mice [44]. A schematic representation for the putative role of phytochemicals in insulin signaling is illustrated in Figure 2.

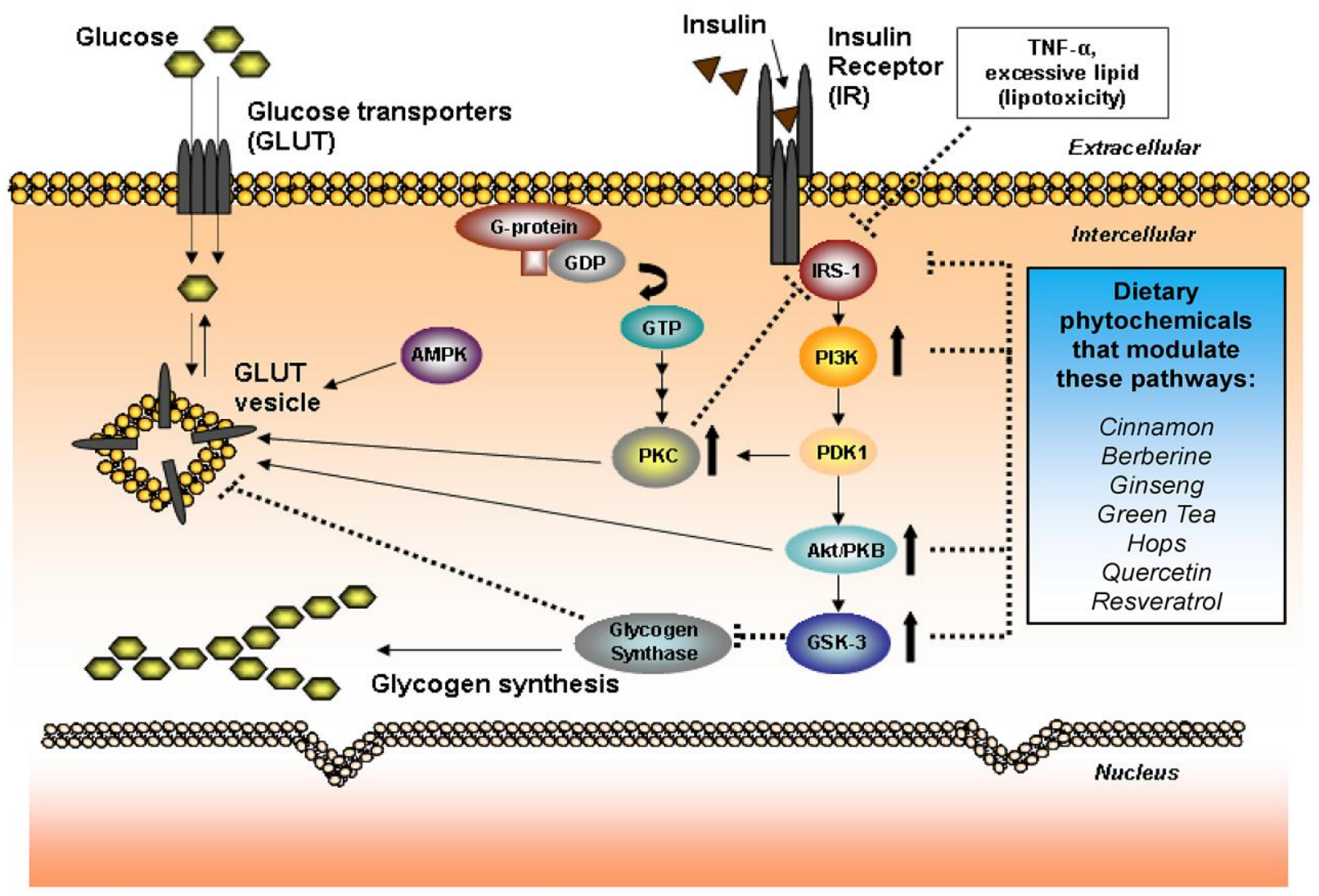

Figure 2. General diagrammatic representation of the insulin-signaling cascade. Insulin is the substrate that leads to a cascade of cellular reactions responsible for glucose and lipid metabolism. Insulin stimulates the insulin receptor (IR) tyrosine kinase, leading to the tyrosine phosphorylation of the insulin receptor substrate (IRS) family of proteins. Activated IRS then displays binding sites for numerous signaling partners such as phosphatidylinositol-3 kinase (PI3K), a key player in insulin function through 
the activation of the Akt/protein kinase $\mathrm{B}(\mathrm{PKB})$. When stimulated, Akt/PKB promotes glycogen synthesis via upregulation of the glycogen synthase enzyme which occurs with inhibition of glycogen synthase kinase (GSK)-3. Additionally, insulin activates glucose uptake via a family of glucose transporters (GLUT). Through negative feedback, PI3K, Akt/PKB, and GSK-3 and can result in serine phosphorylation of IRS, and subsequent inactivation. Activation of G-protein coupled receptors can lead to activation of protein kinase $\mathrm{C}$ (PKC). Excessive stress through inflammatory mediators such as tumor necrosis factor- $\alpha$ (TNF- $\alpha$ ) or through metabolic overflow of lipid from adipose tissue could also impact the insulin signaling cascade. Reproduced with permission from [36].

There are undoubtedly a number of different mechanisms by which phytochemicals from different foods and spices can modulate cellular signaling and metabolic processes. What is emerging from this work is that a complex diet rich in minimally processed vegetables, fruits, grains and legumes supplies an array of phytochemicals that can have a xenohormetic influence on metabolic syndrome.

\section{Clinical intervention with phytochemicals in patients with metabolic syndrome}

Lerman et al. conducted a randomized, twelve-week, dietary intervention trial in metabolic syndrome patients [45]. The control arm received a modified Mediterranean-style low-glycemicload food plan; the intervention arm received the same food plan but also received supplementation with phytosterols, soy protein including isoflavones, hops plant derived rho isoalpha acids, and proanthocyanidins from Acacia nilotica. Results of this trial were very encouraging as both arms experienced improvement in several cardiovascular risk variables [45]. Remarkably, the arm that received additional phytochemicals had a much superior outcome, including a greater percentage of subjects experiencing net resolution of metabolic syndrome [45]. In a retrospective sub-analysis of participants with higher cardiovascular disease risk (i.e. those with metabolic syndrome plus LDL levels in excess of $160 \mathrm{mg} / \mathrm{dl}$ ), Lerman et al. found that the additional phytochemical supplementation was needed in order to adequately reduce multiple biomarkers associated with cardiovascular disease in this high-risk population [46]. Details of these studies are presented in Dr. Robert Lerman's companion article, “A Nutritional Approach to the Metabolic Syndrome".

Other conditions closely associated with insulin resistance have also been investigated. For example, in a study of patients with nonalcoholic steatohepatitis, Sanyal et al. found that patients receiving a supplemental dose of 800-IU of alpha-tocopherol (vitamin E) showed significant improvement in liver histology after 96 weeks compared to those receiving a placebo [47]. Two studies of myo-inositol, a phytochemical found in many foods including barley, the fruit Cucurbita ficifolia, soy, and buckwheat, demonstrated that it has insulin sensitizing effects and reduces dense LDL particles while increasing serum plasmalogens in people with metabolic 
syndrome, as well as improving polycystic ovary syndrome in women with dysfunctional insulin signaling [48, 49].

\section{Conclusions}

The trajectory of current research on the role of phytochemicals in regulating insulin signaling and metabolic syndrome suggests that this will continue to be a fertile area for basic and clinical scientific investigation. Dwyer recently pointed out that phytochemicals and other bioactive substances in food have potential use for safe and effective prevention and management of chronic diseases [50]. The newly recognized roles of specific phytochemicals as modulators of kinase-dependent intracellular signal transduction and also as activators of enzymes such as Sirtuin 1 open the door for robust mechanistic investigations.

It is tantalizing to contemplate the potential evolutionary significance of mechanistic associations between adaptive response processes in plants and animals through phytochemicaldependent functions. Xenohormetic relationships between dietary phytochemicals and consumers of traditional diets may have been evolutionarily established for the conservation of vital cellular processes. Investigation into the mechanisms underlying such relationships may reveal new methods for targeting chronic diseases such as metabolic syndrome.

\section{Acknowledgment}

The author thanks Dr. Ingrid Fricks and Dr. Jyh-Lurn Chang for manuscript preparation.

\section{Conflict of interest}

JS Bland is the Chief Science Officer of Metagenics, Inc. Metagenics is responsible for the publication cost for this article. This review was not sponsored by any funding agency.

\section{References}

1. Himsworth HP. The syndrome of diabetes mellitus and its causes. Lancet. 1949;1:465-73.

2. Reaven GM. Diet and Syndrome X. Curr Atheroscler Rep. 2000;2:503-7.

3. Simmons RK, Alberti KG, Gale EA, Colagiuri S, Tuomilehto J, Qiao Q, et al. The metabolic syndrome: useful concept or clinical tool? Report of a WHO Expert Consultation. Diabetologia. 2010;53:600-5.

4. Grundy SM. Metabolic syndrome pandemic. Arterioscler Thromb Vasc Biol. 2008;28:62936.

5. Eckel RH, Alberti KG, Grundy SM, Zimmet PZ. The metabolic syndrome. Lancet. 2010;375:181-3.

6. Alberti KG, Eckel RH, Grundy SM, Zimmet PZ, Cleeman JI, Donato KA, et al. Harmonizing the metabolic syndrome: a joint interim statement of the International Diabetes Federation Task Force on Epidemiology and Prevention; National Heart, Lung, and Blood 
Institute; American Heart Association; World Heart Federation; International Atherosclerosis Society; and International Association for the Study of Obesity. Circulation. 2009;120:1640-5.

7. Esposito K, Giugliano F, Maiorino MI, Giugliano D. Dietary factors, Mediterranean diet and erectile dysfunction. J Sex Med. 2010;7:2338-45.

8. Lin JW, Caffrey JL, Chang MH, Lin YS. Sex, Menopause, Metabolic Syndrome, and AllCause and Cause-Specific Mortality--Cohort Analysis from the Third National Health and Nutrition Examination Survey. J Clin Endocrinol Metab. 2010;95:4258-67.

9. Marsh KA, Steinbeck KS, Atkinson FS, Petocz P, Brand-Miller JC. Effect of a low glycemic index compared with a conventional healthy diet on polycystic ovary syndrome. Am J Clin Nutr. 2010;92:83-92.

10. Panza F, Frisardi V, Capurso C, Imbimbo BP, Vendemiale G, Santamato A, et al. Metabolic Syndrome and Cognitive Impairment: Current Epidemiology and Possible Underlying Mechanisms. J Alzheimers Dis. 2010;21:691-724.

11. Trichopoulou A, Bamia C, Lagiou P, Trichopoulos D. Conformity to traditional Mediterranean diet and breast cancer risk in the Greek EPIC (European Prospective Investigation into Cancer and nutrition) cohort. Am J Clin Nutr. 2010;92:620-5.

12. Grundy SM, Cleeman JI, Daniels SR, Donato KA, Eckel RH, Franklin BA, et al. Diagnosis and management of the metabolic syndrome: an American Heart Association/National Heart, Lung, and Blood Institute Scientific Statement. Circulation. 2005;112:2735-52.

13. Vrolix R, Mensink RP. Effects of glycemic load on metabolic risk markers in subjects at increased risk of developing metabolic syndrome. Am J Clin Nutr. 2010;92:366-74.

14. Flechtner-Mors M, Boehm BO, Wittmann R, Thoma U, Ditschuneit HH. Enhanced weight loss with protein-enriched meal replacements in subjects with the metabolic syndrome. Diabetes Metab Res Rev. 2010;26:393-405.

15. Marinangeli CP, Jones PJ. Functional food ingredients as adjunctive therapies to pharmacotherapy for treating disorders of metabolic syndrome. Ann Med. 2010;42:317-33.

16. Vannice GK. n-3s from fish and the risk of metabolic syndrome. J Am Diet Assoc. 2010;110:1014-7.

17. Kastorini CM, Panagiotakos DB. The role of the mediterranean diet on the development of the metabolic syndrome. Front Biosci (Elite Ed). 2010;2:1320-33.

18. Serra-Majem L, Roman B, Estruch R. Scientific evidence of interventions using the Mediterranean diet: a systematic review. Nutr Rev. 2006;64:S27-47.

19. Estruch R. Anti-inflammatory effects of the Mediterranean diet: the experience of the PREDIMED study. Proc Nutr Soc. 2010;69:333-40.

20. Esposito K, Maiorino MI, Ceriello A, Giugliano D. Prevention and control of type 2 diabetes by Mediterranean diet: a systematic review. Diabetes Res Clin Pract. 2010;89:97102. 
21. Reisin E. The benefit of the Mediterranean-style diet in patients with newly diagnosed diabetes. Curr Hypertens Rep. 2009;12:56-8.

22. Knoops KT, de Groot LC, Kromhout D, Perrin AE, Moreiras-Varela O, Menotti A, et al. Mediterranean diet, lifestyle factors, and 10-year mortality in elderly European men and women: the HALE project. Jama. 2004;292:1433-9.

23. Schiltz B, Minich DM, Lerman RH, Lamb JJ, Tripp ML, Bland JS. A science-based, clinically tested dietary approach for the metabolic syndrome. Metab Syndr Relat Disord. 2009; 7:187-92.

24. Camargo A, Ruano J, Fernandez JM, Parnell LD, Jimenez A, Santos-Gonzalez M, et al. Gene expression changes in mononuclear cells in patients with metabolic syndrome after acute intake of phenol-rich virgin olive oil. BMC Genomics. 2010;11:253.

25. Lamming DW, Wood JG, Sinclair DA. Small molecules that regulate lifespan: evidence for xenohormesis. Mol Microbiol. 2004;53:1003-9.

26. Walsh MC, Brennan L, Pujos-Guillot E, Sebedio JL, Scalbert A, Fagan A, et al. Influence of acute phytochemical intake on human urinary metabolomic profiles. Am J Clin Nutr. 2007;86:1687-93.

27. Manios Y, Detopoulou V, Visioli F, Galli C. Mediterranean diet as a nutrition education and dietary guide: misconceptions and the neglected role of locally consumed foods and wild green plants. Forum Nutr. 2006;59:154-70.

28. Liu RH. Health benefits of fruit and vegetables are from additive and synergistic combinations of phytochemicals. Am J Clin Nutr. 2003;78:517S-20S.

29. Vincent HK, Bourguignon CM, Taylor AG. Relationship of the dietary phytochemical index to weight gain, oxidative stress and inflammation in overweight young adults. J Hum Nutr Diet. 2010;23:20-9.

30. Babish JG, Pacioretty LM, Bland JS, Minich DM, Hu J, Tripp ML. Antidiabetic screening of commercial botanical products in 3T3-L1 adipocytes and $\mathrm{db} / \mathrm{db}$ mice. J Med Food. 2010;13:535-47.

31. Al-Romaiyan A, Liu B, Asare-Anane H, Maity CR, Chatterjee SK, Koley N, et al. A novel Gymnema sylvestre extract stimulates insulin secretion from human islets in vivo and in vitro. Phytotherapy Research. 2010;24:1370-6.

32. Banos G, Perez-Torres I, El Hafidi M. Medicinal agents in the metabolic syndrome. Cardiovasc Hematol Agents Med Chem. 2008;6:237-52.

33. Mae T, Kishida H, Nishiyama T, Tsukagawa M, Konishi E, Kuroda M, et al. A licorice ethanolic extract with peroxisome proliferator-activated receptor-gamma ligand-binding activity affects diabetes in KK-Ay mice, abdominal obesity in diet-induced obese C57BL mice and hypertension in spontaneously hypertensive rats. J Nutr. 2003;133:3369-77.

34. Minich DM, Bland JS. A review of the clinical efficacy and safety of cruciferous vegetable phytochemicals. Nutr Rev. 2007;65:259-67. 
35. Bakker GC, van Erk MJ, Pellis L, Wopereis S, Rubingh CM, Cnubben NH, et al. An antiinflammatory dietary mix modulates inflammation and oxidative and metabolic stress in overweight men: a nutrigenomics approach. Am J Clin Nutr. 2010;91:1044-59.

36. Minich DM, Bland JS. Dietary management of the metabolic syndrome beyond macronutrients. Nutr Rev. 2008;66:429-44.

37. Lukaczer D, Liska DJ, Lerman RH, Darland G, Schiltz B, Tripp M, et al. Effect of a low glycemic index diet with soy protein and phytosterols on CVD risk factors in postmenopausal women. Nutrition. 2006;22:104-13.

38. Izzo R, de Simone G, Giudice R, Chinali M, Trimarco V, De Luca N, et al. Effects of nutraceuticals on prevalence of metabolic syndrome and on calculated Framingham Risk Score in individuals with dyslipidemia. J Hypertens. 2010;28:1482-7.

39. Barnes S. Nutritional genomics, polyphenols, diets, and their impact on dietetics. J Am Diet Assoc. 2008;108:1888-95.

40. Chung S, Yao H, Caito S, Hwang JW, Arunachalam G, Rahman I. Regulation of SIRT1 in cellular functions: Role of polyphenols. Arch Biochem Biophys. 2010;501:79-90.

41. Hou DX, Kumamoto T. Flavonoids as protein kinase inhibitors for cancer chemoprevention: direct binding and molecular modeling. Antioxid Redox Signal. 2010;13:691-719.

42. Smith U. Impaired ('diabetic') insulin signaling and action occur in fat cells long before glucose intolerance--is insulin resistance initiated in the adipose tissue? Int $\mathrm{J}$ Obes Relat Metab Disord. 2002;26:897-904.

43. Minich DM, Lerman RH, Darland G, Babish JG, Pacioretty LM, Bland JS, et al. Hop and Acacia Phytochemicals Decreased Lipotoxicity in 3T3-L1 Adipocytes, db/db Mice, and Individuals with Metabolic Syndrome. J Nutr Metab. 2010;2010:1-11.

44. Tan MJ, Ye JM, Turner N, Hohnen-Behrens C, Ke CQ, Tang CP, et al. Antidiabetic activities of triterpenoids isolated from bitter melon associated with activation of the AMPK pathway. Chem Biol. 2008;15:263-73.

45. Lerman RH, Minich DM, Darland G, Lamb JJ, Schiltz B, Babish JG, et al. Enhancement of a modified Mediterranean-style, low glycemic load diet with specific phytochemicals improves cardiometabolic risk factors in subjects with metabolic syndrome and hypercholesterolemia in a randomized trial. Nutr Metab (Lond). 2008;5:29.

46. Lerman R, Minich D, Darland G, Lamb J, Chang J, Hsi A, et al. Subjects with elevated LDL cholesterol and metabolic syndrome benefit from supplementation with soy protein, phytosterols, hops rho iso-alph acids, and Acacia nilotica proanthocyanidins. J Clin Lipidol. 2010;4:59-68.

47. Sanyal AJ, Chalasani N, Kowdley KV, McCullough A, Diehl AM, Bass NM, et al. Pioglitazone, vitamin E, or placebo for nonalcoholic steatohepatitis. N Engl J Med. 2010;362:1675-85. 
48. Costantino D, Minozzi G, Minozzi E, Guaraldi C. Metabolic and hormonal effects of myoinositol in women with polycystic ovary syndrome: a double-blind trial. Eur Rev Med Pharmacol Sci. 2009;13:105-10.

49. Maeba R, Hara H, Ishikawa H, Hayashi S, Yoshimura N, Kusano J, et al. Myo-inositol treatment increases serum plasmalogens and decreases small dense LDL, particularly in hyperlipidemic subjects with metabolic syndrome. J Nutr Sci Vitaminol (Tokyo). 2008; 54:196-202.

50. Dwyer JT. Do functional components in foods have a role in helping to solve current health issues? J Nutr. 2007; 137:2489S-92S. 